This is the final peer-reviewed accepted manuscript of:

Dutra, R.F., Zinani, F.S.F., Rocha, L.A.O., Biserni, C.

Constructal design of an arterial bypass graft

(2020) Heat Transfer, 49 (7), pp. 4019-4039.

The final published version is available online at:

https://doi.org/10.1002/htj.21693

Rights / License:

This article may be used for non-commercial purposes in accordance with Wiley Terms and Conditions for Use of Self-Archived Versions. The terms and conditions for the reuse of this version of the manuscript are specified in the publishing policy. For all terms of use and more information see the publisher's website.

This item was downloaded from IRIS Università di Bologna (https://cris.unibo.it/)

When citing, please refer to the published version. 


\title{
CONSTRUCTAL DESIGN OF AN ARTERIAL BYPASS GRAFT
}

\author{
R.F. Dutra ${ }^{1}$, F.S.F. Zinani ${ }^{1 *}$, L.A.O. Rocha ${ }^{1}$ and C. Biserni ${ }^{2}$ \\ ${ }^{1}$ Mechanical Engineering Graduate Program, Universidade do Vale do Rio dos
} Sinos, 93022-750, São Leopoldo, Brazil.

${ }^{2}$ Department of Industrial Engineering (DIN), School of Engineering and Architecture, Alma Mater Studiorum - University of Bologna, Viale Risorgimento 2, 40136 Bologna, Italy

*corresponding author: fzinani@unisinos.br

Abstract. Arterial bypass grafts tend to fail after some years due to Intimal Hyperplasia - an abnormal proliferation of smooth muscle cells that leads to stenosis and graft occlusion. In this regard and based on the Constructal Design method, this study seeks to investigate the effect of geometric parameters - stenosis degree, junction angle and diameter ratio on the flow through a bypass graft circumventing an idealized, partially-stenosed coronary artery. The computational model assumes a steady-state Newtonian fluid flow through an artery stenosis degree from $25 \%$ to $75 \%$. A Computational Fluid Dynamics model and a Response Surface Methodology were employed to assess the effects of the project parameters on pressure drop. As diameter ratio increases to 1 and the junction angle decreases to $30^{\circ}$, the pressure drop decreases and there is a considerable dependence of pressure drop on the stenosis degree. The effects of diameter ratio are more pronounced than those of junction angle on the velocity field and wall shear stress. The application of the Constructal Design method in hemodynamics might be a good alternative to provide configurations with enhanced performance and to provide valuable results to the understanding of biological flows.

Keywords: Constructal Design, blood flow, coronary artery bypass graft, dimensionless pressure drop.

\section{Nomenclature}

D artery diameter

$D_{0} \quad$ stenosis diameter

$D_{1} \quad$ graft diameter

$D_{i j} \quad$ strain rate tensor

$D_{1} / D_{\text {, opt }} \quad$ optimum diameter ratio 
$L \quad$ length

$m \quad$ number of verification points

$N \quad$ number of mesh elements $\quad[-]$

$\tilde{p} \quad$ dimensionless pressure drop $[-]$

$\tilde{p}_{\text {min }} \quad$ minimum dimensionless pressure drop $\quad[-]$

$\tilde{p}_{\text {obs }} \quad$ dimensionless pressure drop observed from verification points $\quad[-]$

$\tilde{p}_{\text {pred }} \quad$ dimensionless pressure drop predicted from response surface [-]

Re Reynolds number $\quad[-]$

$S \quad$ stenosis degree $\quad[-]$

$U_{m} \quad$ average velocity $\left[\mathrm{m} \mathrm{s}^{-1}\right]$

$u_{i} \quad$ velocity vector $\quad\left[\mathrm{m} \mathrm{s}^{-1}\right]$

$\tilde{u}_{i} \quad$ dimensionless velocity field $\quad[-]$

$V \quad$ artery volume $\left[\mathrm{m}^{3}\right]$

$\begin{array}{lll}V_{l} & \text { graft volume } & {\left[\mathrm{m}^{3}\right]}\end{array}$

$\tilde{X}$ dimensionless position $\quad[-]$

$\begin{array}{lll}x & \text { position vector } & {[\mathrm{m}]}\end{array}$

$\tilde{x}_{i} \quad$ dimensionless position vector $\quad[-]$

\section{Greek symbols}

$\begin{array}{clc}\alpha & \text { junction angle } & {[-]} \\ \alpha, \text { opt } & \text { optimum junction angle } & {[-]} \\ \Delta p & \text { pressure drop } & {[\mathrm{Pa}]} \\ \eta & \text { viscosity function } & {[\mathrm{Pa} \mathrm{s}]} \\ \mu & \text { dynamic viscosity } & {[\mathrm{Pa} \mathrm{s}]} \\ \rho & \text { mass density } & {\left[\mathrm{kg} \mathrm{m}^{-3}\right]} \\ \dot{\gamma} & \text { shear rate } & {\left[\mathrm{s}^{-1}\right]} \\ \tau^{*} & \text { normalized shear stress } & {[-]} \\ \tau_{i j} & \text { extra-stress tensor } & {[\mathrm{Pa}]} \\ \tilde{\tau}_{i j} & \text { dimensionless extra vector tensor field } & {[-]}\end{array}$




\section{INTRODUCTION}

The accumulation of fat in arteries' walls can block partly or completely the flow of blood as well as cause atherosclerosis, which consists of a stiffening of the walls of these vessels (KU et al., 1985). As explained by Tian et al. (2013) and Liu et al. (2015) this abnormal accumulation is commonly designated as stenosis. Patients under these conditions can lose quality of life due to the loss of oxygenation of organs, tissues or the brain and are at risk for heart attacks or strokes. According to Guerciotti et al. (2017), one type of palliative treatment for high-risk patients is the coronary artery bypass graft (CABG) surgery, which consists of bypassing a stenotic region in order to restore proper blood flow to the heart. The main factor that affects graft patency is intimal hyperplasia (IH) - an abnormal proliferation of smooth muscle cells that is mainly observed between the graft and the coronary artery, resulting in the reduction of the lumen of the graft and leading to restenosis and graft occlusion (BASSIOUNY et al., 1992).

Over the last two decades, computational fluid dynamics (CFD) methods have been used to investigate a possible correlation between hemodynamics in CABGs and IH development and aid in the development of an optimal graft design. Lei et al. (1997) analyzed the distribution of wall shear stress gradients for conventional geometries and demonstrated that it was possible to design an optimal graft geometry that significantly reduced wall shear stress gradients. Bertolotti and Deplano (2000) used a three-dimensional numerical model with different locations of the stenosis relative to the downstream junction and concluded that the risks of intimal hyperplasia at the anastomosis might be reduced by increasing the distance between the stenosis and the junction. Lee et al. (2001) studied the flow behavior of a complete bypass graft and a 100\% occluded artery with different Reynolds number and junction angles. They demonstrated that the entrance and the exit junctions of the bypass were the two critical locations where the flow became disordered generally with recirculation zones. Cole et al. (2002) performed numerical simulations in a specific modified geometry of the Taylor graft in a totally-occluded artery and discovered that this modification led to hemodynamic benefits preventing intimal hyperplasia. Leuprecht et al. (2002) investigated the influence on the hemodynamic behavior and wall stresses caused by geometric conditions and different compliance of a conventional graft and the Miller-cuff type graft. Their results led to the conclusion that the better patency of the Miller-cuff prosthesis could be due to its larger space, demonstrating the considerable influence of asymmetries and local geometric irregularities on flow pattern. Chua et al. (2005a) investigated sleeve models that exhibited optimized 
hemodynamics flows to be used as mechanical connectors between the bypass graft and host artery at the distal anastomosis, eliminating the need for quality suturing. Three models were studied varying the diameter and height of the sleeves and it was concluded that the sleeve model, which had the same diameter of the artery and the graft, exhibited improving hemodynamics flow characteristics. In a second study, Chua et al. (2005b) studied the flow characteristics of a complete coronary artery bypass graft (CABG) connecting two different arteries, the Aorta and the coronary artery, and found that smaller grafting angle and smooth geometry reduced the high wall shear stress gradient in junctions, thereby improving the longterm graft patency rate. Politis et al. (2007) compared simulated blood flow in four different configurations of simplified composite arterial coronary grafts and suggested that the $\mathrm{Y}$ - and T-grafts were the best cases in terms of hemodynamic performance. Ko et al. (2007) performed simulations in a stenosed artery with a complete bypass graft to verify the influence in flow fields of different severity of occlusions $(0 \%, 70 \%, 80 \%, 90 \%$, and $100 \%$ area stenosis $)$ in a fixed junction angle and graft diameter. They pointed out the influences of stenosis severity on the flow fields and suggested that this could be one of the causes of restenosis in the host artery with bypass graft implantation. Fan et al. (2008) studied numerically and experimentally the hemodynamics effects of an S-type bypass, demonstrating the occurrence of a swirling flow that altered the overall flow pattern and eliminated the low WSS zone along the host artery floor. Ko et al. (2008) compared the effects on the flow field of three different junction angles $\left(45^{\circ}, 60^{\circ}\right.$ and $\left.75^{\circ}\right)$ in a $70 \%$ area-occluded artery with a complete bypass graft and concluded that flow features (e.g., recirculation, secondary flow and WSS distribution) in the stenosed host artery and the bypass graft were closely related with the junction angle. Xiong and Chong (2008) and Do et al. (2010) investigated numerically the diameter ratio and the angle between the graft and host artery and both suggested that a higher diameter and a junction angle between $30^{\circ}$ to $45^{\circ}$ would enhance long-term performance and lessen the development of IH. Vimmr et al. (2012) performed several numerical simulations of a complete three-dimensional coronary bypass model as a function of three geometrical parameters (stenosis degree, junction angle, and diameter ratio) and discovered that the diameter ratio was the most crucial parameter for coronary artery bypass grafting (CABG). Roos et al. (2013) focused their graft study in the illustration of potential benefits from the introduction of a fluid deflector to prevent the suture line from unhealthily high wall shear stress results. Their results suggested that a fluid deflector may be useful and beneficial in increasing the patency of the optimized graft. Fan et al. (2016) numerically studied the distribution of hemodynamic parameters in the left internal mammary artery (LIMA) bypass graft with stenosis of different degrees at various periods after surgical 
revascularization postoperative. It was discovered that hemodynamics were associated with multiple morphometric parameters; i.e., graft configuration, severity of stenosis and LIMA geometry. Liu et al. (2016) numerically investigated the effectiveness of helical arterial grafts by comparing the hemodynamic performance of conventional and this kind of graft with different positions and smooth tapers. Their findings suggested that the new helical graft with taper would significantly enhance helical flow, which would reduce the thrombus formation and IH. Post et al. (2019) focused their analysis to estimate changes in fluid flow and wall shear stress as a function of graft compliance with the host artery and concluded that high compliance grafts displayed minimal changes in fluid flow and arterial remodeling.

According to Constructal Law, stated by Adrian Bejan in 1996, "for a finite-size flow system to persist in time (to live) it must evolve with freedom in such a way that it provides easier access to imposed currents that that flow through it" (BEJAN, 1997). Constructal Law deals with the physical concepts of life, evolution, design, performance and time arrow (BEJAN, 2016). Under Constructal Theory, evolution and design in nature are deterministic because the living systems evolve in such a way to decrease resistance to flow (BEJAN and LORENTE, 2011). The growth of scientific research concerning Constructal Law has been documented in review articles (REIS, 2006; BEJAN and LORENTE, 2011; CHEN, 2012) and books (BEJAN, 1997; BEJAN and LORENTE, 2008; BEJAN and ZANE, 2012; BEJAN, 2016).

Constructal Design is the study and mathematical modeling of flow systems' evolution. It has the capability to explain the configuration of existing systems in nature and to design flow systems in engineering. This design methodology has the objectives of accessing the effects of shape and geometry in flow performance and finding the optimal geometry according to Constructal Law (ROCHA et al., 2017). The applications of Constructal Design cover many engineering fields such as heat and mass transfer, renewable energy, manufacture and materials (ROCHA et al., 2017; RAZERA et al., 2018; FAGUNDES et al., 2019). Until now the few applications of Constructal Theory in medicine were within the field of cancer treatments, as studied by Wang et al. (2007) and Lucia and Grisolia (2018), and vision, in two papers by Lucia et al. (2016) and Lucia et al. (2017).

Based on the Constructal Design method, this study seeks to investigate the effect of geometric parameters on the flow through a bypass graft circumventing an idealized, partiallystenosed coronary artery. To this end, a Computational Fluid Dynamics model and Design of Experiments and Response Surface methodologies were used to evaluate the effect of geometric 
parameters on pressure drop in different flow conditions. To the best of the author's knowledge, the present study is the first one to apply the Constructal Design method in hemodynamics to investigate blood flow devices. The introduction of the Constructal Design method to the field of hemodynamics brings a valuable tool to the understanding of biological problems since the bypass geometry is known to affect the blood flow field significantly and to play an important role in potential graft failure due to intimal hyperplasia.

\section{METHODOLOGY}

\subsection{Constructal design}

The problem domain is shown in Fig. (1). It is an idealized version of an artery partially obstructed by fatty material deposition and implanted with a graft with both proximal and distal anastomoses. The artery is represented as the host artery with a diameter equal to $D$ and length equal to $L$. The main tube undergoes a stenosis that reduces it to diameter $D_{0}$. The geometry is symmetric over the center of the stenosis in the axial direction. The graft is placed at a distance $L_{2}$ from the center of the stenosis and its diameter is denoted $D_{1}$. The junction angle is $\alpha$ and the graft diameter is denoted $D_{1} . L_{3}$ is the distance from the center where the stenosis begins. The detailed locations of heel, toe, bed, inner, outer and side-walls are indicated in Fig. (1).

The flow problem consists of a fluid which enters the domain at the tube inlet with average velocity $U_{m}$. Depending on flow conditions and geometry configuration, the flow is partially deviated through the bypass. It is assumed that the tube walls are rigid, impermeable and non-slip. The flow is also assumed to be three-dimensional, steady, incompressible and laminar.

The full computational model for the geometry is depicted in Fig. (1) with main tube extensions of 25 diameters upstream and downstream $\left(L_{5}=25 . D\right.$ and $\left.L_{6}=25 . D\right)$ to obtain a fully developed flow. A uniform velocity profile, equal to $U_{m}$, was imposed at the inlet. At the outlet, a pressure outlet was imposed as boundary condition. For all simulations, the host artery diameter $D$ is equal to $3 \mathrm{~mm}$, corresponding to an average value of the right coronary artery (BERTOLOTTI et al., 2001).

Since the stenosis is usually formed by material deposition, the main tube volume is considered as its external volume was not narrowed:

$$
V=\pi{\frac{D^{2}}{4}}^{2} L
$$


where $V$ is the total artery volume, $D$ is the artery diameter and $L$ is the total artery length.

The graft volume is

$$
V_{1}=\pi{\frac{D_{1}}{4}}^{2} L_{4}
$$

where $V_{1}$ is the total graft volume, $D_{1}$ is the graft diameter and $L_{4}$ is the total graft length.

The stenosis degree is calculated as

$$
S=\frac{D-D_{0}}{D} x 100 \%
$$

where $S$ is the stenosis degree and $D_{0}$ is the diameter at the center of the stenosis.

The ratios $L / D, L_{2} / D$ and $L_{3} / D$ were defined as constants as detailed in Tab. (1). A baseline case from literature (VIMMR et al., 2012) was used in the definition of these values.

Three values of stenosis degree $S(25 \%, 50 \%$ and $75 \%)$ were evaluated at three different Reynolds Number, (150, 250 and 400). Blood is modelled as an incompressible Newtonian fluid with density $\rho=1000 \mathrm{~kg} / \mathrm{m}^{3}$ and dynamic viscosity $\mu=0.0035$ Pa.s (KO et al., 2007). The assumption of blood as Newtonian fluid is acceptable and used by other studies in the hemodynamic area, e.g., Ko et al. (2007), Ko et al. (2008), Xiong, and Chong (2008) and Vimmr et al. (2012).

Constructal Theory assumes that living systems evolve limited by space (ROCHA et al., 2017). Accordingly, Constructal Theory systems must evolve in order to provide easier access to its flows (BEJAN and LORENTE, 2008). To this end, it was considered that the dimensionless pressure drop $\tilde{p}$ along the length $L$ should be as low as possible.

Thus, an optimization problem was formulated as: "Find the minimum $\tilde{p}$. The design variables are the diameter ratio $D_{1} / D$ and the junction angle $\alpha$. The restrictions are constant $L / D$, $L_{2} / D$ and $L_{3} / D$." Therefore, the degrees of freedom for this problem are the diameter ratio $D_{1} / D$ and the junction angle $\alpha$. A search is conducted for the diameter ratio $D_{1} / D$ and junction angle $\alpha$ that minimize the value of the pressure drop $\tilde{p}_{\min }$ for specific combinations of $S$ and Reynolds Number $R e$. To corroborate the results that minimize pressure drop, the effect of the geometric variation on velocity contours and wall shear stress (WSS) arisen in the host artery are also analyzed. Figure 2 details all the steps required by the Constructal Design methodology. 


\subsection{Mathematical modeling}

The mathematical modeling for the flow through the artery and bypass model consists of the mass and momentum balance equations for incompressible fluids. These equations written in their dimensionless form are:

$$
\begin{aligned}
& \frac{\partial \widetilde{u}_{i}}{\partial \tilde{x}_{i}}=0 \\
& \tilde{u}_{i} \frac{\partial \widetilde{u}_{i}}{\partial \tilde{x}_{j}}=-\frac{\partial \tilde{p}}{\partial \tilde{x}_{i}}+\frac{1}{R e} \frac{\partial \tilde{x}_{i j}}{\partial x_{j}}
\end{aligned}
$$

where $\tilde{u}_{i}$ denotes the dimensionless velocity field, $\tilde{x}_{i}$ the dimensionless position vector, $\tilde{p}$ the dimensionless pressure drop, $\tilde{\tau}_{i j}$ the dimensionless extra stress tensor field, $R e$ the Reynolds number such that:

$$
\tilde{u}_{i}=\frac{u_{i}}{U_{m}} ; \quad \tilde{x}_{i}=\frac{x}{D} ; \quad \tilde{p}=\frac{\Delta p}{\rho U_{m}{ }^{2}} ; \quad \tilde{\tau}=\frac{\tau_{i j}}{\left(U_{m} \mu\right) / D} \quad R e=\frac{\rho U_{m} D}{\mu}
$$

where $\Delta p$ is the pressure drop along $L, \rho$ is the fluid density, $\mu$ is the fluid viscosity and $U_{m}$ is the average velocity at the inlet.

The constitutive equation for the extra stress is that of a generalized Newtonian liquid:

$$
\tau_{i j}=2 \eta(\dot{\gamma}) D_{i j}
$$

where $\eta(\dot{\gamma})$ is the viscosity function and $D_{i j}$ is the strain rate tensor, given as the symmetric part of the velocity gradient tensor (SLATTERY, 1999). For a Newtonian fluid, $\eta(\dot{\gamma})$ is constant and equal to $\mu$.

\subsection{Numerical method and computational grid}

In order to solve the system of partial differential equations, it was employed the Finite Volume Method (PATANKAR, 1980) using the ANSYS/FLUENT v. 18.2 (ANSYS, 2015). A pressure-based solver was used with a pressure-velocity coupling method and second-order 
interpolation functions for pressure and velocity fields. All calculations were conducted in double-precision representation of real numbers. The iterative algorithm was a false transient. The mesh was parameterized to keep proportional the element sizes according to the stenosis configuration and diameter ratio studied. Depending on the configuration, a total of 500,000 to 950,000 tetrahedral finite elements were necessary to mesh the computational domain accurately. Along the walls, prismatic layers elements were used in order to better capture the boundary layer. Figure 3 presents a sample of the computational mesh for the model with detailed views at the cross section in the bypass and native stenotic artery. As convergence criterion, scaled residuals of each equation at an iteration were used and compared with a userdefined convergence criteria equal to $10^{-6}$ for velocity and pressure fields.

The Grid Convergence Index (GCI) method was applied for different values of junction angle $\alpha$ and diameter ratio $D_{1} / D$ in the three values of stenosis degree $(S=25 \%, 50 \%$, and 75\%). As explained by Celik et al. (2008), this method is useful for calculation and reporting of discretization error estimates in CFD simulations where experimental data may not be available for comparison.Table 2 summarizes these results where $N$ represents the number of elements. It can be verified that the maximum $G C I$ was $1.82 \%$, refining the mesh in a factor of $15 \%$ to $30 \%$. It is important to observe that, based on experience and not on formal derivation, a GCI value of 5\% is considered acceptable for this method (CELIK et al., 2008).

\subsection{Design of experiments and response surface methodology}

To investigate the effects of the junction angle $\alpha$ and the artery diameter ratio $D_{1} / D$ on the pressure drop along the length $L$, the Response Surface methodology available in ANSYS Design Xplorer 18.2 was applied (ANSYS, 2016). A sparse grid method (MONTGOMERY, 2013) was employed for the design of experiments to build the response surfaces and represent $\tilde{p}$ as a function of the degrees of freedom $D_{1} / D$ and $\alpha$, within the ranges $0.1 \leq D_{1} / D \leq 1.0$ and $30^{\circ} \leq \alpha \leq 70^{\circ}$. Sparse Grid is an adaptive model driven by the accuracy defined by the user. Initially, the program calculated four design points located at the edges and one design point located at the center of the response surface. Then, the response surface was elaborated with a maximum number of 1,000 design points per surface. This method increases the accuracy of the response surface by automatically refining the matrix of design points in locations where the relative error of the output parameter is higher, i.e., it refines design points only in the directions necessary (ANSYS, 2016). Figure 4 illustrates a response surface example with a different matrix of design points. It is noteworthy that each design point represents a specific 
bypass configuration within the ranges $0.1 \leq D_{1} / D \leq 1.0$ and $30^{\circ} \leq \alpha \leq 70^{\circ}$. In this study, the number of points needed to construct each surface ranged from 200 to 300 .

After building the response surfaces, the method suggests verification points. Ten verification points (individual simulations) were used for each response surface. Here, the root mean square error (RMSE) is employed as an indicator of the quality of the response surface:

$$
R M S E=\sqrt{\frac{1}{m} \sum_{i=1}^{m}\left(\frac{\tilde{p}_{p r e d, i}-\tilde{p}_{o b s, i}}{\tilde{p}_{o b s, i}}\right)^{2}} \times 100
$$

where $\tilde{p}_{\text {pred }}$ is the value of $\tilde{p}$ predicted from response surface, $\tilde{p}_{\text {obs }}$ is the value of $\tilde{p}$ observed from the verification points, and $m$ is the number of verification points.

In all cases there was good agreement between individual simulations and the response surfaces. The maximum RMSE for the response surfaces presented in this work was $1.33 \%$.

\section{RESULTS AND DISCUSSION}

\subsection{Model verification}

Preliminary tests were performed using the numerical model and their results for the wall shear stress (WSS) were compared with those of Ko et al. (2007) for the case of Reynolds number $R e$ equal to 250 , blood viscosity $\mu$ equal to $0.0035 \mathrm{~kg} / \mathrm{m} . \mathrm{s}$, blood density $\rho$ equal to $1000 \mathrm{~kg} / \mathrm{m}^{3}$ and the parameters of the arterial graft $D_{1} / D$ equal to 1 , junction angle $\alpha$ equal to $45^{\circ}$ and stenosis degree $S$ equal to $70 \%$. The shear stress found at each point was normalized by the shear stress of a fully developed condition in the host artery. Three positions were verified on the wall artery (inner, outer and side wall, as presented in Fig. (1)).

Figure 5 presents the results of the verification for the inner wall and outer wall. The side wall results are not included for simplicity since they were similar to the outer wall results. It can be verified that for most points there was good agreement between the present results and literature. 


\subsection{Response surfaces}

Figure 6 shows the response surfaces that represent $\tilde{p}$ as a function of the degrees of freedom, $D_{1} / D$ and $\alpha$, within the ranges $0.1 \leq D_{1} / D \leq 1.0$ and $30^{\circ} \leq \alpha \leq 70^{\circ}$. Each response surface represents the results of stenosis degree $S$ equal to $25 \%, 50 \%$ and $75 \%$ at Reynolds Number $R e$ equal to 150,250 and 400. It is possible to observe that the nine response surfaces had a specific optimal point that minimized the dimensionless pressure drop $\tilde{p}$. For each case, a value of $D_{1} / D$ and $\alpha$ where $\tilde{p}$ is minimum was obtained. In all situations, as the aspect ratio $D_{1} / D$ increased to 1 and the junction angle, $\alpha$, decreased to $30^{\circ}, \tilde{p}$ decreased. However, as the stenosis degree became larger, i.e. the flow highly deviated through the bypass and the influence of $\alpha$ in $\tilde{p}$ became almost unnoticeable. These results showed that the diameter ratio $D_{1} / D$ had a more significant effect on the pressure drop than $\alpha$. The prominent influence of the $D_{l} / D$ ratio compared to the $\alpha$ angle had been confirmed experimentally (TSUKUI et al., 2017) and numerically (XIONG and CHONG, 2008; DO et al., 2010; VIMMR et al., 2012) in idealized steady and pulsatile stenotic flows. Tsukui et al. (2017) also confirmed that a smaller junction angle $(\alpha)$ yielded lower energy loss at bypass graft.

Table 3 summarizes the optimal geometry results for the nine configurations. It is possible to notice a considerable dependence of $\tilde{p}$ on the stenosis degree $S$. Also, the optimum point for all cases was $D_{1} / D$, opt equal to 1 and $\alpha$, opt equal to $30^{\circ}$. This result indicated that by increasing the aspect ratio $D_{1} / D$ and decreasing the angle $\alpha$ a better result would be obtained. However, this situation would be impractical from the surgical standpoint because a graft of difficult suture would be produced (VIMMR et al., 2012). As a possible solution to this problem, Chua et al. (2005a) proposed sleeve models that could be used as mechanical connectors between the bypass graft and host artery, eliminating the need for quality suturing.

As according to Constructal Law, everything that flows generates forms and structures over time in order to facilitate its movement through mediums that offer resistances to the flow (BEJAN and ZANE, 2012). So, by applying Constructal Design methodology, the optimum points found here were in accordance with previous studies that evaluated the graft design with other methodologies. Xiong and Chong (2008) speculated that a graft with a diameter of about 1 to 1.5 times larger than that of the host artery, and a junction angle in the range of $30^{\circ}-45^{\circ}$ would improve hemodynamics. Do et al. (2010) found a similar result, where the junction angle is $40^{\circ}$ with a diameter ratio equal to 1.6. Vimmr et al. (2012) concluded that the most favorable flow field was observed for the bypass model with a diameter ratio equal to 1 while reducing the probability of bypass failure due to thrombosis or intimal hyperplasia. 


\subsection{Velocity fields}

Velocity field data is presented at $R e$ equal to 250 and for $S$ equal to $25 \%, 50 \%$, and $75 \%$ to corroborate the results found on the response surfaces for the optimal bypass geometry. The main focus was on the isolated effect caused by the variation of the diameter ratio $D_{1} / D$ and junction angle $\alpha$. For each stenosis degree, velocity contours are shown in Fig. (7), (8) and (9) at different diameter ratios $\left(D_{1} / D\right.$ equal to $0.5 ; 0.7$; and 1.0$)$ for a fixed junction angle, equal to $30^{\circ}(\alpha$, opt found in Tab. (3)).

As expected from section 3.2, the increase of aspect ratio $D_{1} / D$ provided a greater flow deviation through the bypass. It is worth noting that for $S$ equal to $25 \%$ the placement of the bypass graft did not significantly affect blood flow. As the degree of stenosis increased, the use of the bypass became more effective. These findings were consistent with Ko et al. (2007) and Vimmr et al. (2012), who asserted that stenosis degree smaller than 50\% were commonly described as hemodynamically insignificant because there was no impact on the blood supply to downstream tissues. Furthermore, according to Fan et al. (2016) mild stenosis could significantly reduce the resistance and induce a small pressure gradient from the inlet of a bypass, causing a competitive flow through it and reducing its long term patency.

In addition, with the increase of $D_{1} / D$, larger recirculation zones appeared for stenosis of $50 \%$ ( $\tilde{x}=-2$ to 0 and $\tilde{x}=1$ to 3 ) and $75 \%(\tilde{x}=-2$ to 0 and $\tilde{x}=1$ to 3 ). This situation was already well reported by several authors. Bertolotti et al. (2001) and Ko et al. (2007) observed the recirculation zone upstream of the junction and pointed out that, downstream of the junction, the greater the bypass flow (i.e., as the stenosed severity increases), the greater the distance to obtain the maximum velocity at the center of the artery and the greater the distributing areas of recirculation zones. Lee et al. (2001) concluded that the entrance and the exit junctions of the bypass were the two critical locations where the curved, twisted and disturbed flow in the bypass was prone to damage the particles in the blood flow. Hence, recirculation zones next to the occlusion allow the damaged particles and substances to accumulate. Because of this phenomenon bypass surgery tends to fail after some years, being well recognized that nonuniform hemodynamics contributes to restenosis and the risk of thrombosis due to the possibility of blood cell accumulation (OWIDA et al., 2012; VIMMR et al., 2012).

Jet blood flow was observed in the post stenotic region $(\tilde{x}=0)$, especially at severe degrees of stenosis $(S=75 \%)$ and when $D_{1} / D$ had lower values. The complexity of these flow patterns had been analyzed in the most recent studies in the hemodynamic area at stenotic arteries without bypass graft. Conti et al. (2016), Sood et al. (2018) and Andersson et al. (2019) 
reported in their studies that such crossing pattern of the jet could impair essential endothelial functions and increase the susceptibility and progression of vascular diseases. The greater the degree of stenosis, the more distinct, stronger and eccentric was the jet flow. However, its role as a pathological determinant was still less understood (ANDERSSON et al., 2019).

Referring now to Fig. (10), (11) and (12), velocity contours are presented at different junction angles ( $\alpha$ equal to $30^{\circ} ; 40^{\circ} ; 50^{\circ} ; 60^{\circ}$; and $70^{\circ}$ ) for a fixed diameter ratio equal to 1 $\left(D_{1} / D\right.$, opt found in Tab. (3)). For any degree of stenosis, it is noteworthy that at lower junction angles (Fig. (10a), (11a) and (12a)), smaller peaks of velocity appeared along with the domain, i.e., blood flow was more uniform in both the bypass and the artery. Upstream of the stenosis no significant differences in velocity contours as well as in recirculation zones were noticed. Downstream of the stenosis, at $S$ equal to 50\% (Fig. (11)) and 75\% (Fig. (12)), an accentuation of a recirculation zone could be seen near the toe $(\tilde{x}=3$ to 5$)$ with the increase of the junction angle. Besides, at $S$ equal to $75 \%$ (Fig. (12)), the increase of $\alpha$ promoted a greater direction of flow against the bed of the artery ( $\tilde{x}=3$ to 4 ). These findings were in line with previous steady and pulsatile studies that stated the anastomotic angles greatly dominate the flow conditions around the heel, toe, and across the artery bed. Lee et al. (2001) and Do et al. (2010) concluded that a smaller angle meant weaker secondary flow and smoother overall flow but in practice it took a longer suture line which would be more vulnerable to thrombosis. Chua et al. (2005a) and Owida et al. (2012) observed that high gradients of velocity were found in the post stenotic region, which might be the reason for the $\mathrm{IH}$ to be more prevalent at this region. Regardless of the angle studied in a 70\% stenotic artery, Ko et al. (2008) stated that there are four low-velocity regions in the artery and one in the graft. They also concluded that the increase of anastomotic angle caused less percentage of the mass flow rate flowing into the bypass graft but did not influence the flow patterns. Vimmr et al. (2012) pointed out as a practicable solution an intermediate angle that ensured a relatively uniform flow field but did not require a complicated implementation technique and a longer suture line.

\subsection{Wall Shear Stress (WSS)}

Intimal hyperplasia formation is associated with low WSS values and there is a risk of plaque rupture at high shear stresses (OJHA, 1994; HARUGUCHI et al., 2003; PEIFFER et al., 2013). In this section the focus is on the shear stress behavior at artery wall. Results are shown at $R e$ equal to 250 , critical stenosis degree equal to $50 \%$ and $75 \%$ and, similarly to velocity 
contours, the focus is on the isolated effect on WSS caused by the variation of the diameter ratio $D_{1} / D$ and junction angle $\alpha$.

The shear stress found in each point was normalized by the shear stress at a fully developed condition in the host artery. Remarkable results are pointed out at three positions on the wall artery (inner, outer and side wall, as presented in Fig. (13) to (18)). In any of the three wall positions studied, it was possible to observe that with the increment of the stenosis degree higher WSS values were obtained in the constricted area $(\tilde{x}=0)$. This result was in agreement with the conclusions of Ko et al. (2007) and Vimmr et al. (2012). Also, by reducing the diameter ratio, there was an expressive increase in WSS values in the area of stenosis $(\tilde{x}=0)$. A less representative increase in WSS occured in same region with increment of junction angle.

At the inner wall (Fig. (13) and (14)), increasing the diameter ratio or reducing junction angle induced higher WSS values in the entrance of bypass ( $\tilde{x}=-2$ to -1$)$ and toe regions $(\tilde{x}=$ 3 to 4 ). These results suggested that by increasing the aspect ratio $D_{1} / D$ and decreasing the angle $\alpha$, more blood flow was deviated through the bypass. Another observation at the inner wall in Fig. (13b) and Fig. (14b) were the negative values of WSS in the recirculation zones ( $\tilde{x}=3$ to 4). It was possible to conclude that the increase in junction angle provided a more intense recirculation zone at the toe region ( $\tilde{x}=3$ to 4$)$. This result was in contrast to Vimmr et al. (2012) which did not observe an appreciable influence of junction angle in the pre and poststenotic regions. However, in the vicinity of the toe, a larger angle exposed the wall to lower shear stress. Do et al. (2010) also pointed out that by changing the junction angle the WSS locations were more pronounced around the graft and at the bed near the toe.

On the outer wall (Fig. (15) and (16)) it is noted the influence on WSS caused by the variation of diameter ratio and junction angle. In Fig. (15a), in the post stenotic region $(\tilde{x}=2$ to 4 ) the increase in $D_{1} / D$ caused higher WSS values. In Fig. (16b), the increase in junction angle caused a peak of shear stress in the artery bed ( $\tilde{x}=3$ to 4$)$. Chua et al. (2005a) and Ko et al. (2008) also reported high gradients of WSS in the post stenotic region at the artery bed by increasing the junction angle, which may be the reason for the thicker intimal hyperplasia at the floor of host artery. All these observations were also noted on the side wall (Fig. (17) and (18)). The difference is in Fig. (17b) and (18b) in the region upstream of the stenosis ( $\tilde{x}=-3$ to -2 ), where greater negative WSS values were observed for larger angles. 


\section{CONCLUDING REMARKS}

In this work, it was investigated the effects of geometric parameters in different flow conditions of a bypass graft in an idealized, partially-stenosed coronary artery. Using Constructal Design associated with Design of Experiments and Response Surface methodologies, nine response surfaces were generated, each one representing the results of stenosis degree $S$ equal to $25 \%, 50 \%$, and $75 \%$ and for Reynolds number equal to 150, 250 and 400. It was found for which values of $D_{l} / D$ and $\alpha$ the dimensionless pressure drop $\tilde{p}$, was minimized. In all situations, as the diameter ratio increased to 1 and the junction angle decreased to $30^{\circ}, \tilde{p}$ decreased. Also, it was possible to notice a considerable dependence of $\tilde{p}$ on the stenosis degree $S$. The optimum point for all cases was $D_{1} / D$, opt equal to 1 and $\alpha$, opt equal to $30^{\circ}$, which was confirmed by previous studies. It was also evaluated the isolated effects on velocity contours and wall shear stress (WSS) caused by the variation of the diameter ratio $D_{1} / D$ and junction angle $\alpha$. The results showed that $D_{1} / D$ had more significant effects than $\alpha$. It is noteworthy that the Design of Experiments and Response Surface methodologies can be used in the future to evaluate other hemodynamic parameters to improve the results found so far.

At this point, some limitations of this study should be mentioned. First of all, a steadystate condition was applied while the blood flow is known to be pulsating. Secondly, the blood was assumed as a Newtonian fluid, which may affect the results found at low shear stress rates. Moreover, the grafts and arteries were assumed as rigid walls and idealized without considering a patient-specific vascular model. In addition, literature does not yet provide many experimental data that are essential for validation and clinical adoption of any proposed configuration.

Despite the above-mentioned simplifications and assumptions, by applying Constructal Design methodology, the main conclusions and the optimal graft design found in this paper are in accordance with previous studies that evaluated the graft design with other methodologies. It is worth mentioning that until now the few applications of Constructal theory in medicine had been with respect to cancer treatments in two works. One, by Wang et al. (2007) evaluated the crucial problem of keeping the temperature of the healthy tissue surrounding the tumor below a certain threshold so as not to damage the tissue itself. The other, by Lucia and Grisolia (2018) studied the entropy generation related to the $\mathrm{pH}$ changes obtained by ionic transport through a membrane related to mitosis/apoptosis ratio and fundamental to evaluate the probability of evolution of cancer. Other two works in the vision area used an approach based on Constructal Law: one to analyse the pressure inside the eye's anterior chamber in relation to 
the biomechanical properties of corneas (LUCIA et al., 2016) and the other verified how the chloride ions fluxes can determine the water inflow and outflow and to understand how intraocular pressure is controlled by these fluxes (LUCIA et al., 2017). Finally, starting from the outcomes obtained here, it is evident that the introduction of the Constructal Design method in the area of hemodynamics can provide valuable results for problems that literature still does not provide a definitive clarification.

\section{ACKNOWLEDGEMENTS}

The author R.F. Dutra acknowledges the agency CAPES (Coordination for the Improvement of Higher Education Personnel- Brasília - DF - Brazil) for a Master's Degree scholarship. Authors F.S.F. Zinani and L.A.O. Rocha are grant holders of CNPq (National Counsel of Technological and Scientific Development- Brasília - DF - Brazil), process numbers 307827/2018-6 and 307847/2015-2, respectively. We acknowledge Unisinos Office of Research and Graduate Studies (UAPPG) and CAPES for financial support. The author C. Biserni was sponsored by the Italian Ministry for Education, University and Research.

\section{REFERENCES}

ANDERSSON, Magnus; EBBERS, Tino; KARLSSON, Matts. Characterization and estimation of turbulence-related wall shear stress in patient-specific pulsatile blood flow. Journal of Biomechanics, v. 85, p. 108-117, 2019.

<https://doi.org/10.1016/j.jbiomech.2019.01.016>

ANSYS. Ansys Fluent User's Guide. Canonsburg, 2015.

ANSYS. Design Xplorer User's Guide. Release 17.2. Canonsburg, 2016.

BASSIOUNY, Hisham S.; WHITE, Scott; GLAGOV, Seymour; CHOI, Eric; GIDDENS, Don P.; ZARINS, Christopher K. Anastomotic intimal hyperplasia: Mechanical injury or flow induced. Journal of Vascular Surgery, v. 15, n. 4, p. 708-717, 1992.

<https://doi.org/10.1067/mva.1992.33849>

BEJAN, A. Advanced Engineering Thermodynamics. 2 ed, Wiley, New York, 1997.

BEJAN, A; LORENTE, S. Design with Constructal Theory. Wiley, Hoboken, 2008.

BEJAN, A.; LORENTE, S. The constructal law and the evolution of design in nature. Physics of Life Reviews, v. 8, p. 209-240, 2011. <https://doi.org/10.1016/j.plrev.2011.05.010> 
BEJAN, A.; ZANE, J. P. Design in Nature: How the Constructal Law Governs Evolution in Physics, Biology, Technology, and Social Organization. Doubleday, New York, 2012.

BEJAN, A. The Physics of Life, St. Martin's Press, New York, 2016.

BERTOLOTTI, C.; DEPLANO, V.; FUSERI, J.; DUPOUY, P. Numerical and experimental models of post-operative realistic flows in stenosed coronary bypasses. Journal of Biomechanics, v. 34, n. 8, p. 1049-1064, 2001. <https://doi.org/10.1016/S0021-9290(01)00027-6>

BERTOLOTTI, C; DEPLANO, V. Three-dimensional numerical simulations of flow through a stenosed coronary bypass. Journal of Biomechanics, v. 33, p. 1011-1022, 2000. <https://doi.org/10.1016/S0021-9290(00)00012-9>

CELIK, I. B.; GHIA, U.; ROACHE, P. J.; FREITAS, C. J.; COLEMAN, H.; RAAD, P. E., 2008. Procedure for Estimation and Reporting of Uncertainty Due to Discretization in CFD Applications. Journal of Fluids Engineering, v. 130, p. 128-131.

CHEN, L. Progress in study on constructal theory and its applications. Science China Technological Sciences, v. 55, n. 3, p. 802-820, 2012.

<https://doi.org/10.1007/s11431-011-4701-9>

CHUA, Leok Poh; TONG, Jia Hui; ZHOU, Tongming. Numerical simulation of steady flows in designed sleeve models at distal anastomoses. International Communications in Heat and Mass Transfer, v. 32, n. 5, p. 707-714, 2005.

<http://dx.doi.org/10.1016/j.icheatmasstransfer.2004.08.025>

CHUA, Leok Poh; ZHANG, Junmei; ZHOU, Tongming. Numerical study of a complete anastomosis model for the coronary artery bypass. International Communications in Heat and Mass Transfer, v. 32, n. 3-4, p. 473-482, 2005.

<http://dx.doi.org/10.1016/j.icheatmasstransfer.2004.03.016>

COLE, J. S.; WATTERSON, J. K.; O'REILLY, M. J. G. Numerical investigation of the haemodynamics at a patched arterial bypass anastomosis. Medical Engineering and Physics, v. 24, n. 6, p. 393-401, 2002. <https://doi.org/10.1016/S1350-4533(02)00038-3>

CONTI, Michele; LONG, Chris; MARCONI, Michele; BERCHIOLLI, Raffaella; BAZILEVS, Yuri; REALI, Alessandro. Carotid artery hemodynamics before and after stenting: A patient specific CFD study. Computers and Fluids, v. 141, p. 62-74, 2016. <http://dx.doi.org/10.1016/j.compfluid.2016.04.006>

DO, Hung; OWIDA, Amal A.; YANG, William; MORSI, Yos S. Numerical simulation of the haemodynamics in end-to-side anastomoses. International Journal for Numerical Methods in Fluids, v. 67, p. 638-650, 2010. 〈http://dx.doi.org/10.1002/fld.2381>

FAGUNDES, T. M.; LORENZINI, G.; ESTRADA, E. da S. D.; ISOLDI, L. A.; DOS SANTOS, E. D.; ROCHA, L. A. O.; DA SILVA NETO, A. J. Constructal Design of Conductive Asymmetric Tri-Forked Pathways. Journal of Engineering Thermophysics, v. 28, n. 1, p. 2642, 2019. <http://dx.doi.org/10.1134/S181023281901003X> 
FAN, Tingting; LU, Yuan; GAO, Yan; MENG, Jie; TAN, Wenchang; HUO, Yunlong; KASSAB, Ghassan S. Hemodynamics of left internal mammary artery bypass graft: Effect of anastomotic geometry, coronary artery stenosis, and postoperative time. Journal of Biomechanics, v. 49, n. 5, p. 645-652, 2016.

<http://dx.doi.org/10.1016/j.jbiomech.2016.01.031>

FAN, Yubo; XU, Zaipin; JIANG, Wentao; DENG, Xiaoyan; WANG, Ke; SUN, Anqiang. An S-type bypass can improve the hemodynamics in the bypassed arteries and suppress intimal hyperplasia along the host artery floor. Journal of Biomechanics, v. 41, n. 11, p. 2498-2505, 2008. <http://dx.doi.org/10.1016/j.jbiomech.2008.05.008>

GUERCIOTTI, Bruno; VERGARA, Christian; IPPOLITO, Sonia; QUARTERONI, Alfio; ANTONA, Carlo; SCROFANI, Roberto. A computational fluid-structure interaction analysis of coronary Y-grafts. Medical Engineering and Physics, v. 47, p. 117-127, 2017. <http://dx.doi.org/10.1016/j.medengphy.2017.05.008>

HARUGUCHI, Hiroaki; TERAOKA, Satoshi. Intimal hyperplasia and hemodynamic factors in arterial bypass and arteriovenous grafts: A review. Journal of Artificial Organs, v. 6, n. 4, p. 227-235, 2003. <http://dx.doi.org/10.1007/s10047-003-0232-x>

IASIELLO, Marcello; VAFAI, Kambiz; ANDREOZZI, Assunta; BIANCO, Nicola. Analysis of non-Newtonian effects within an aorta-iliac bifurcation region. Journal of Biomechanics, v. 64, p. 153-163, 2017. <https://doi.org/10.1016/j.jbiomech.2017.09.042>

KO, T. H.; TING, K.; YEH, H. C. Numerical investigation on flow fields in partially stenosed artery with complete bypass graft: An in vitro study. International Communications in Heat and Mass Transfer, v. 34, n. 6, p. 713-727, 2007.

<http://dx.doi.org/10.1016/j.icheatmasstransfer.2007.03.010>

KO, T. H.; TING, K.; YEH, H. C. A numerical study on the effects of anastomotic angle on the flow fields in a stenosed artery with a complete bypass graft. International Communications in Heat and Mass Transfer, v. 35, n. 10, p. 1360-1367, 2008. <http://dx.doi.org/10.1016/j.icheatmasstransfer.2008.06.010>

KU, David N; GIDDENS, Don P.; ZARINS, Christopher K.; GLAGOV, Seymour. Pulsatile Flow and Atherosclerosis in the Human Carotid Bifurcation. Ateriosclerosis, v. 5, p. 293-302, 1985. <https://doi.org/10.1161/01.ATV.5.3.293>

LEE, D.; SU, J. M.; LIANG, H. Y. A numerical simulation of steady flow fields in a bypass tube. Journal of Biomechanics, v. 34, n. 11, p. 1407-1416, 2001.

<https://doi.org/10.1016/S0021-9290(01)00131-2>

LEI, M.; ARCHIE, J. P.; KLEINSTREUER, C. Computational design of a bypass graft that minimizes wall shear stress gradients in the region of the distal anastomosis. Journal of Vascular Surgery, v. 25, n. 4, p. 637-646, 1997.

<https://doi.org/10.1016/S0741-5214(97)70289-1>

LEUPRECHT, Armin; PERKTOLD, Karl; PROSI, Martin; BERK, Thomas; TRUBEL, Wolfgang; SCHIMA, Heinrich. Numerical study of hemodynamics and wall mechanics in 
distal end-to-side anastomoses of bypass grafts. Journal of Biomechanics, v. 35, n. 2, p. 225 236, 2002. <https://doi.org/10.1016/S0021-9290(01)00194-4>

LIU, Guiying; WU, Jianhuang; GHISTA, Dhanjoo N.; HUANG, Wenhua; WONG, Kelvin K. L. Hemodynamic characterization of transient blood flow in right coronary arteries with varying curvature and side-branch bifurcation angles. Computers in Biology and Medicine, v. 64, p. 117-126, 2015. <http://dx.doi.org/10.1016/j.compbiomed.2015.06.009>

LIU, Xiao; WANG, Libing; WANG, Zhenze; LI, Zhengxing; KANG, Hongyan; FAN, Yubo; SUN, Anqiang; DENG, Xiaoyan. Bioinspired helical graft with taper to enhance helical flow. Journal of Biomechanics, v. 49, n. 15, p. 3643-3650, 2016.

<http://dx.doi.org/10.1016/j.jbiomech.2016.09.028>

LUCIA, Umberto; GRISOLIA, Giulia; DOLCINO, Daniela; ASTORI, Maria Rosa; MASSA, Eugenio; PONZETTO, Antonio. Constructal approach to bio-engineering: the ocular anterior chamber temperature. Scientific Reports, v. 6, p. 1-6, 2016.

<http://dx.doi.org/10.1038/srep31099>

LUCIA, Umberto; GRISOLIA, Giulia; ASTORI, Maria Rosa. Constructal law analysis of $\mathrm{Cl}^{-}$ transport in eyes aqueous humor. Scientific Reports, v. 7, n. 1, p. 8-11, 2017.

<http://dx.doi.org/10.1038/s41598-017-07357-8>

LUCIA, Umberto; GRISOLIA, Giulia. Constructal law and ion transfer in normal and cancer cells. Proceedings of the Romanian Academy, Series A, v. 19, Special Issue, p. 213-218, 2018. <https://academiaromana.ro/sectii2002/proceedings/doc2018-1s/continut/213-218.pdf>

MONTGOMERY, D.C. Design and Analysis of Experiments, 8. ed., John Wiley \& Sons, New Jersey, 2012.

OJHA, Matadial. Wall Shear Stress Temporal Gradient and Anastomotic Intimal Hyperplasia. Circulation Research, v. 74, p. 1227-1231, 1994.

<https://doi.org/10.1161/01.res.74.6.1227>

OWIDA, Amal Ahmed; DO, Hung; MORSI, Yos S. Numerical analysis of coronary artery bypass grafts: An over view. Computer Methods and Programs in Biomedicine, v. 108, n. 2, p. 689-705, 2012. 〈http://dx.doi.org/10.1016/j.cmpb.2011.12.005>

PATANKAR, S. V. Numerical Heat Transfer and Fluid Flow. McGraw-Hill, New York, 1980.

PEIFFER, Veronique; SHERWIN, Spencer J.; WEINBERG, Peter D. Does low and oscillatory wall shear stress correlate spatially with early atherosclerosis? A systematic review. Cardiovascular Research, v. 99, n. 2, p. 242-250, 2013.

<https://doi.org/10.1093/cvr/cvt044>

POLITIS, A. K.; STAVROPOULOS, G. P.; CHRISTOLIS, M. N.; PANAGOPOULOS, F. G.; VLACHOS, N. S.; MARKATOS, N. C. Numerical modeling of simulated blood flow in idealized composite arterial coronary grafts: Steady state simulations. Journal of Biomechanics, v. 40, n. 5, p. 1125-1136, 2007.

<https://doi.org/10.1016/j.jbiomech.2006.05.008> 
POST, Allison; DIAZ-RODRIGUEZ, Patricia; BALOUCH, Bailey; PAULSEN, Samantha; WU, Siliang; MILLER, Jordan; HAHN, Mariah; COSGRIFF-HERNANDEZ, Elizabeth. Elucidating the role of graft compliance mismatch on intimal hyperplasia using an ex vivo organ culture model. Acta Biomaterialia, v. 89, p. 84-94, 2019.

$<$ https://doi.org/10.1016/j.actbio.2019.03.025>

RAZERA, A. L.; DA FONSECA, R. J. C.; ISOLDI, L. A.; DOS SANTOS, E. D.; ROCHA, L. A. O.; BISERNI, C. Constructal design of a semi-elliptical fin inserted in a lid-driven square cavity with mixed convection. International Journal of Heat and Mass Transfer, v. 126, p. 81-94, 2018. <https://doi.org/10.1016/j.ijheatmasstransfer.2018.05.157>

REIS, A. H. Constructal theory: from engineering to physics, and how flow systems develop shape and structure. Applied Mechanics Reviews, v. 59, p. 269-282, 2006.

<https://doi.org/10.1115/1.2204075>

ROCHA, L. A. O.; LORENTE, S.; BEJAN, A. Constructal Theory in Heat Transfer. In: KULACKI F. Handbook of Thermal Science and Engineering. Springer, 2017. Chap. 1, p. 1-32. <https://doi.org/10.1007/978-3-319-32003-8_66-1>

ROOS, M. W.; WADBRO, E.; BERGGREN, M. Computational estimation of fluid mechanical benefits from a fluid deflector at the distal end of artificial vascular grafts. Computers in Biology and Medicine, v. 43, n. 2, p. 164-168, 2013.

<http://dx.doi.org/10.1016/j.compbiomed.2012.11.012>

SlAttery, J., C. Advanced Transport Phenomena. Cambridge University Press, New York, 1999.

SOOD, Tapan; ROY, Somnath; PATHAK, Manabendra. Effect of pulse rate variation on blood flow through axisymmetric and asymmetric stenotic artery models. Mathematical Biosciences, v. 298, n. February, p. 1-18, 2018.

<https://doi.org/10.1016/j.mbs.2018.01.008>

TIAN, Fang Bao; ZHU, Luoding; FOK, Pak Wing; LU, Xi Yun. Simulation of a pulsatile nonNewtonian flow past a stenosed 2D artery with atherosclerosis. Computers in Biology and Medicine, v. 43, n. 9, p. 1098-1113, 2013.

<https://doi.org/10.1016/j.compbiomed.2013.05.023>

TSUKUI, Hiroyuki; SHINKE, Manabu; PARK, Young Kwang; YAMAZAKI, Kenji. Longer coronary anastomosis provides lower energy loss in coronary artery bypass grafting. Heart and Vessels, v.32, n. 1, p. 83-89, 2017.

<http://dx.doi.org/10.1007/s00380-016-0880-4>

VIMMR, Jan; JONÁŠOVÁ, Alena; BUBLÍK, Ondřej. Effects of three geometrical parameters on pulsatile blood flow in complete idealised coronary bypasses. Computers and Fluids, v. 69, p. 147-171, 2012. <https://doi.org/10.1016/j.compfluid.2012.08.007>

WANG, Haojie; DAI, Weizhong; BEJAN, Adrian. Optimal temperature distribution in a 3D triple-layered skin structure embedded with artery and vein vasculature and induced by 
electromagnetic radiation. International Journal of Heat and Mass Transfer, v. 50, p. 1843 1854, 2007. <http://dx.doi.org/10.1016/j.ijheatmasstransfer.2006.10.005>

XIONG, F. L.; CHONG, C. K. A parametric numerical investigation on haemodynamics in distal coronary anastomoses. Medical Engineering and Physics, v. 30, n. 3, p. 311-320, 2008. https://doi.org/10.1016/j.medengphy.2007.04.013 


\section{FIGURES DESCRIPTION:}

Figure 1 - Representation of the problem domain.

Figure 2 - Flowchart with application of Constructal Design and Sparse Grid methods for the present problem.

Figure 3 - Isometric view of the computational mesh for the model (a) with a detailed view at the cross section in the bypass and native stenotic artery (b) and a front mesh view of the bypass (c) and stenosis region (d).

Figure 4 - Representation of a response surface with different matrix of design points generated by the Sparse Grid method.

Figure 5 - Model verification. Results of the normalized shear stress, $\tau^{*}$, at the inner wall (a) and outer wall (b).

Figure 6 - Response surfaces representing $\tilde{p}$ as a function of $D_{1} / D$ and $\alpha$ for the stenosis degree and Reynolds number as follows: (a) $R e=150 / S=25 \%$; (b) $R e=150 / S=50 \%$; (c) $R e=150$ / $S=75 \%$; (d) $R e=250 / S=25 \%$; (e) $R e=250 / S=50 \%$; (f) $R e=250 / S=75 \%$; (g) $R e=400 / S=25 \%$; (h) $R e=400 / S=50 \%$; (i) $R e=400 / S=75 \%$.

Figure 7 - Effect provided by the variation of diameter ratio, $D_{1} / D$, in a fixed junction angle, $\alpha$,opt $=30^{\circ}$, on velocity contours for stenosis degree, $S=25 \%$ and $R e=250$. (a) $D_{1} / D=0.5$; (b) $D_{1} / D=0.7$; (c) $D_{1} / D=1.0$.

Figure 8 - Effect provided by the variation of diameter ratio, $D_{1} / D$, in a fixed junction angle, $\alpha$,opt $=30^{\circ}$, on velocity contours for stenosis degree, $S=50 \%$ and $R e=250$. (a) $D_{1} / D=0.5$; (b) $D_{1} / D=0.7$; (c) $D_{1} / D=1.0$.

Figure 9 - Effect provided by the variation of diameter ratio, $D_{1} / D$, in a fixed junction angle, $\alpha$, opt $=30^{\circ}$, on velocity contours for stenosis degree, $S=75 \%$ and $R e=250$. (a) $D_{1} / D=$ 0.5 ; (b) $D_{1} / D=0.7$; (c) $D_{1} / D=1.0$.

Figure 10 - Effect provided by the variation of junction angle, $\alpha$, in a fixed diameter ratio, $D_{1} / D$, opt $=1$, on velocity contours for stenosis degree, $S=25 \%$ and $\operatorname{Re}=250$. (a) $\alpha=30^{\circ}$; (b) $\alpha$ $=40^{\circ}$; (c) $\alpha=50^{\circ}$; (d) $\alpha=60^{\circ}$; (e) $\alpha=70^{\circ}$.

Figure 11 - Effect provided by the variation of junction angle, $\alpha$, in a fixed diameter ratio, $D_{1} / D$, opt $=1$, on velocity contours for stenosis degree, $S=50 \%$ and $\operatorname{Re}=250$. (a) $\alpha=30^{\circ}$; (b) $\alpha$ $=40^{\circ}$; (c) $\alpha=50^{\circ}$; (d) $\alpha=60^{\circ}$; (e) $\alpha=70^{\circ}$.

Figure 12 - Effect provided by the variation of junction angle, $\alpha$, in a fixed diameter ratio, $D_{1} / D$, opt $=1$, on velocity contours for stenosis degree, $S=75 \%$ and $\operatorname{Re}=250$. (a) $\alpha=30^{\circ}$; (b) $\alpha$ $=40^{\circ}$; (c) $\alpha=50^{\circ}$; (d) $\alpha=60^{\circ}$; (e) $\alpha=70^{\circ}$. 
Figure 13 - Results of normalized shear stress, $\tau^{*}$, provided by the variation of (a) diameter ratio, $D_{1} / D$ and (b) junction angle, $\alpha$ at the inner wall for $S=50 \%$ and $R e=250$.

Figure 14 - Results of normalized shear stress, $\tau^{*}$, provided by the variation of (a) diameter ratio, $D_{1} / D$ and (b) junction angle, $\alpha$ at the inner wall for $S=75 \%$ and $R e=250$.

Figure 15 - Results of normalized shear stress, $\tau^{*}$, provided by the variation of (a) diameter ratio, $D_{1} / D$ and (b) junction angle, $\alpha$ at the outer wall for $S=50 \%$ and $\operatorname{Re}=250$.

Figure 16 - Results of normalized shear stress, $\tau^{*}$, provided by the variation of (a) diameter ratio, $D_{1} / D$ and (b) junction angle, $\alpha$ at the outer wall for $S=75 \%$ and $\operatorname{Re}=250$.

Figure 17 - Results of normalized shear stress, $\tau^{*}$, provided by the variation of (a) diameter ratio, $D_{l} / D$ and (b) junction angle, $\alpha$ at the side wall for $S=50 \%$ and $R e=250$.

Figure 18 - Results of normalized shear stress, $\tau^{*}$, provided by the variation of (a) diameter ratio, $D_{1} / D$ and (b) junction angle, $\alpha$ at the side wall for $S=75 \%$ and $\operatorname{Re}=250$. 
Table 1 - Geometric parameters for artery and graft build up.

\begin{tabular}{cc}
\hline Parameters & Values \\
\hline$L / D$ & 16.67 \\
$L_{2} / D$ & 2.5 \\
$L_{3} / D$ & 1 \\
\hline
\end{tabular}


Table 2 - Some samples of Grid Convergence Index (GCI) for different bypass configurations at $\operatorname{Re}=250$.

\begin{tabular}{ccccccccc}
\hline & Case 1 & Case 2 & Case 3 & Case 4 & Case 5 & Case 6 & Case 7 & Case 8 \\
\hline$D_{1} / D$ & 0,1 & 0,1 & 0,1 & 0,55 & 1 & 1 & 1 & 1 \\
$\alpha$ & $30^{\circ}$ & $30^{\circ}$ & $70^{\circ}$ & $50^{\circ}$ & $30^{\circ}$ & $30^{\circ}$ & $70^{\circ}$ & $70^{\circ}$ \\
$S$ & $25 \%$ & $75 \%$ & $75 \%$ & $50 \%$ & $25 \%$ & $75 \%$ & $25 \%$ & $75 \%$ \\
$N 1$ & 529,773 & 820,701 & 669,261 & 731,031 & 640,062 & 940,363 & 510,872 & 803,049 \\
$N 2$ & 431,466 & 709,991 & 570,235 & 564,503 & 533,546 & 786,550 & 434,428 & 651,633 \\
$N 3$ & 364,651 & 542,664 & 454,099 & 425,013 & 455,450 & 574,455 & 368,760 & 490,328 \\
$\tilde{p}_{N 1}$ & 2.712 & 133.408 & 133.475 & 4.796 & 2.258 & 2.659 & 2.362 & 3.924 \\
$\tilde{p}_{N 2}$ & 2.715 & 133.493 & 133.874 & 4.835 & 2.326 & 2.662 & 2.415 & 3.928 \\
$\tilde{p}_{, N 3}$ & 2.723 & 136.925 & 134.216 & 4.847 & 2.331 & 2.676 & 2.437 & 3.929 \\
$\boldsymbol{G C I}$ & $\mathbf{0 . 2 4 \%}$ & $\mathbf{0 . 1 0 \%}$ & $\mathbf{0 . 7 1 \%}$ & $\mathbf{0 . 4 2 \%}$ & $\mathbf{1 . 4 4 \%}$ & $\mathbf{0 . 5 5 \%}$ & $\mathbf{1 . 8 2 \%}$ & $\mathbf{1 . 6 6 \%}$ \\
\hline
\end{tabular}


Table 3 - Optimum results for each stenosis degree, at $R e$ equal to 150, 250 and 400.

\begin{tabular}{ccccc}
\hline$R e$ & $S$ & $\tilde{p}_{, \min }$ & $D_{1} / D$, opt & $\alpha$, opt \\
\hline 150 & $25 \%$ & 3.315 & 1 & $30^{\circ}$ \\
150 & $50 \%$ & 3.685 & 1 & $30^{\circ}$ \\
150 & $75 \%$ & 3.978 & 1 & $30^{\circ}$ \\
250 & $25 \%$ & 2.186 & 1 & $30^{\circ}$ \\
250 & $50 \%$ & 2.435 & 1 & $30^{\circ}$ \\
250 & $75 \%$ & 2.659 & 1 & $30^{\circ}$ \\
400 & $25 \%$ & 1.574 & 1 & $30^{\circ}$ \\
400 & $50 \%$ & 1.755 & 1 & $30^{\circ}$ \\
400 & $75 \%$ & 1.942 & 1 & $30^{\circ}$ \\
\hline
\end{tabular}

